\title{
Chloride to Creatinine Ratio Measurement
}

National Cancer Institute

\section{Source}

National Cancer Institute. Chloride to Creatinine Ratio Measurement. NCI Thesaurus.

Code C79440.

The determination of the ratio of chloride compared to creatinine present in a sample.

The measurement may be expressed as a ratio or percentage. 